University of Nebraska - Lincoln

DigitalCommons@University of Nebraska - Lincoln

Publications from USDA-ARS / UNL Faculty

U.S. Department of Agriculture: Agricultural

Research Service, Lincoln, Nebraska

4-2006

\title{
Crossover Interactions for Grain Yield in Multienvironmental Trials of Winter Wheat
}

\author{
R. Mishra \\ Mahyco Research Center \\ P. Stephen Baenziger \\ University of Nebraska-Lincoln, pbaenziger1@unl.edu \\ W. Ken Russell \\ University of Nebraska-Lincoln \\ Robert A. Graybosch \\ University of Nebraska-Lincoln, bob.graybosch@ars.usda.gov \\ David D. Baltensperger \\ University of Nebraska, dbaltensperger@tamu.edu
}

See next page for additional authors

Follow this and additional works at: https://digitalcommons.unl.edu/usdaarsfacpub

Part of the Agricultural Science Commons

Mishra, R.; Baenziger, P. Stephen; Russell, W. Ken; Graybosch, Robert A.; Baltensperger, David D.; and Eskridge, Kent M., "Crossover Interactions for Grain Yield in Multienvironmental Trials of Winter Wheat" (2006). Publications from USDA-ARS / UNL Faculty. 910.

https://digitalcommons.unl.edu/usdaarsfacpub/910

This Article is brought to you for free and open access by the U.S. Department of Agriculture: Agricultural Research Service, Lincoln, Nebraska at DigitalCommons@University of Nebraska - Lincoln. It has been accepted for inclusion in Publications from USDA-ARS / UNL Faculty by an authorized administrator of DigitalCommons@University of Nebraska - Lincoln. 


\section{Authors}

R. Mishra, P. Stephen Baenziger, W. Ken Russell, Robert A. Graybosch, David D. Baltensperger, and Kent M. Eskridge 


\title{
Crossover Interactions for Grain Yield in Multienvironmental Trials of Winter Wheat
}

\author{
R. Mishra, P. Stephen Baenziger,* W. Ken Russell, Robert A. Graybosch, \\ David D. Baltensperger, and Kent M. Eskridge
}

\begin{abstract}
Crossover interactions (COIs) are changes in ranks among cultivars across environments. Breeders are concerned about COIs because their frequency affects how well rankings from one environment predict rankings in another environment. This research was undertaken to determine the frequency and distribution of COIs for grain yield within years in two regional trials of winter wheat (Triticum aestivum L.). The trials were in Nebraska and in the south-central USA (SCUS). Each trial had four environments per year, and results from 1998, 1999, and 2000 were considered. Significance of $\mathrm{COI}$ for each pair of lines in each pair of environments within years was determined by a $t$ test with an interaction-wise Type 1 error rate. Grain yield varied significantly across environments in both trials in all years, and in the within-year analyses the line $\times$ environment interaction was always highly significant. In the Nebraska trial, the frequency of COIs was less than expected by chance only in one pair of environments in 1 yr. Nonetheless, because estimates suggested the line $\times$ environment $\times$ year variance was substantially greater than the line $\times$ environment variance, this significant occurrence of COIs did not support breeding for local adaptation. In the SCUS trial, a lower frequency of COIs occurred than in the Nebraska trial. In both trials, frequency of COIs in a pair of environments was not closely related to the difference in mean yield between those environments, which raised the usefulness of categorizing environments as low-stress or as high-stress for the purpose of selection.
\end{abstract}

G ENOTYPE $\times$ ENVIRONMENT interaction is a problem for plant breeders because it causes uncertainty when translating the performance of a cultivar relative to other cultivars in one environment to performance in a different environment. The contribution of different years to the genotype $\times$ environment interaction in continental regions is widely accepted by most plant breeders of annual crops. Consequently, before the release of a new cultivar, plant breeders will evaluate that cultivar across multiple years and locations. Nonetheless, plant breeders make decisions every year on the basis of single-year data. In fact, most potential cultivars are discarded after a single year of testing. Therefore, understanding relationships among testing locations within years, as well as across years, is important for

R. Mishra, Mahyco Research Center, P O Box 76, Dawalwadi, Jalna431203, India; P.S. Baenziger and W.K. Russell, Dep. of Agronomy and Horticulture, Univ, of Nebraska, Lincoln, NE 68583-0915; R.A. Graybosch, Agronomy \& Horticulture, USDA-ARS, 344 Keim Hall, UNL, East Campus, Lincoln, NE 68583; D.D. Baltensperger, Panhandle Research and Extension Center, University of Nebraska, 4502 Avenue I, Scottsbluff, NE 69361; K.M. Eskridge, Department of Statistics, Univ. of Nebraska, Lincoln, NE 68583-0712. Nebraska Agric. Res. Div., Journal Series No.14925. Received 16 Aug. 2005. *Corresponding author (pbaenziger@unl.edu).

Published in Crop Sci.46:1291-1298 (2006).

Crop Breeding \& Genetics

doi:10.2135/cropsci2005.08-0259

(c) Crop Science Society of America

677 S. Segoe Rd., Madison, WI 53711 USA selecting the best test sites and for interpreting data from cultivar testing programs.

A multitude of statistical procedures have been used to explore relationships among testing locations, including much focus in the recent decade on ordination procedures such as the additive main effects and multiplicative interaction model (Gauch and Zobel, 1988). Another more simplistic approach that has been used frequently by plant breeders is to categorize testing sites into low-stress and high-stress environments. The question then arises whether selection under low-stress or under high-stress conditions is more likely to result in development and identification of cultivars with good performance across a range of environmental conditions. Rosielle and Hamblin (1981) addressed this question theoretically and concluded that compared with direct selection for productivity (mean performance in all environments), selection for tolerance to stress (difference in performance between low- and high-stress environments) usually will result in reduced productivity in low-stress environments and across all environments. Experimental results on this issue have been mixed. Some studies have supported the strategy of selecting under low-stress environments (Frey, 1964; Shabana et al., 1980; Johnson and Geadelmann, 1989; Byrne et al., 1995; Braun et al., 1996), whereas others have indicated that selection under stressful conditions was more advantageous (Atlin and Frey, 1989; Van Oosterom et al., 1993; Ceccarelli, 1994; Ceccarelli and Grando, 1996).

When genotype $\times$ environment interaction is important, Allen et al. (1978) showed that test environments should be chosen such that the product of the square root of broad-sense heritability $(H)$ in the test environments and the simple correlation between genetic values in the target and test environments is at a maximum. A correlation of less than one between genotypic means in two environments occurs whenever relative differences between genotypes change across the environments, but these changes may not always result in changes in rank. Thus, the simple correlation may not give a true indication of the value of an environment in predicting the outcomes at other environments (Russell et al., 2003). Haldane (1946) maintained that genotype $\times$ environment interaction is of consequence in breeding only when a COI exists and others have likewise noted the importance of COI in crop selection (Fox and Rosielle, 1982; Baker, 1988). In assessing relationships among environments, a breeder should know whether significant COI exists. Ideally, the target and corresponding testing environments should be grouped so that COI within each group is minimal.

Abbreviations: $H$, broad-sense heritability; COI, crossover interaction I, irrigated; NI, nonirrigated; SCUS, south-central USA. 
Two approaches have been developed for measuring the significance of COIs. One approach uses a $t$ test in which the difference between two genotypes in each of two environments is compared with a critical value. If the differences are of opposite sign in the two environments and both are greater than the critical value, then a significant COI is declared. Azzalini and Cox (1984) defined a value of $t$ that gives an experiment-wise error rate, whereas Cornelius et al. (1992) developed a less conservative test by using a value of $t$ that gives an interaction-wise error rate. In a second approach, Gail and Simon (1985) proposed a maximum likelihood test to determine significance of COI between two "treatments" (genotypes) across a series of "groups" (environments).

Despite the impact that COI should have on breeding strategy, little is known about the importance of COI in yield trials of winter wheat in the Great Plains. Our objectives were (i) to determine the frequency and pattern of significant COIs in two regional trials of winter wheat, (ii) to consider the implications of the observed frequency and pattern on breeding and testing strategies, (iii) to compare the relationships between environments on the basis of COI to those based on simple correlations between genotypic means in different environments, and (iv) to evaluate the correspondence of frequency of COIs in pairs of environments to the difference in mean grain yield of those environments. This last objective revisited the issue of the relative value of data from high- and low-yielding environments in selection programs.

\section{MATERIALS AND METHODS Nebraska Regional Trial}

Fifty winter wheat lines were evaluated in four environments (locations) in 1998, 1999, and 2000. Except for several checks, the entries were experimental lines developed by the wheat-breeding program at the University of Nebraska. The majority of these experimental lines was being evaluated across multiple locations for the first time. A few of the experimental lines and some of the checks were evaluated in more than $1 \mathrm{yr}$, but most of the lines evaluated in each year were unique. The environments were Lincoln (southeast), North Platte (central), Sidney (west), and Alliance (northwest). In Nebraska, rainfall decreases and elevation increases in an east-to-west direction. Thus, these environments were expected to produce a substantial range in yield levels. To increase this range and make it more likely to encompass the range observed in yield levels by farmers in Nebraska, the Sidney location was irrigated. At least $5 \%$ of the winter wheat production in Nebraska has occurred under irrigation in recent years (Nebraska Agricultural Statistics Service, 2002). In 2000, the experiment at North Platte was discarded because of hail damage.

At all environments in each year, the experimental design was a randomized complete block with two replications. The seeding rate at the nonirrigated environments was $67.2 \mathrm{~kg}$ $\mathrm{ha}^{-1}$, but it was $101.0 \mathrm{~kg} \mathrm{ha}^{-1}$ at Sidney. Plot size at the nonirrigated environments was four rows by $2.4 \mathrm{~m}$ long with $30 \mathrm{~cm}$ between rows. All four rows were combined, except at Lincoln in 1998, where only the middle two rows were cut and then threshed to determine grain yield. At Sidney, the plot size was the same length, but the number of rows was six and the middle four rows were combined. At each environment, agronomic practices representative of the local production area were used.

\section{South-Central USA (SCUS) Regional Trial}

Forty-five lines were evaluated at Clovis, NM, and at Bushland, TX, as part of the Southern Performance Regional Nursery in 1998, 1999, and 2000. Bushland is located in the northern Texas and Clovis is located in east-central New Mexico. As with the Nebraska trial, most of the lines were experimental lines and most were evaluated only in $1 \mathrm{yr}$. Unlike the experimental lines in the Nebraska trial, however, these lines typically had more selection history for adaptation to the range of environments observed within states across multiple years.

At each location in each year, a nonirrigated and an irrigated trial were evaluated, providing four testing environments (location $\times$ irrigation treatments) per year. At both locations, fertilization was applied at local customary rates, whereas irrigation was applied to maximize grain yield. The seeding rate for the nonirrigated and irrigated trials was 39.2 and $100.9 \mathrm{~kg} \mathrm{ha}^{-1}$ at Clovis and 43.7 and $82.9 \mathrm{~kg} \mathrm{ha}^{-1}$ at Bushland. The experimental design for each trial was a randomized complete block with three replications, except at Clovis in 1998 both the nonirrigated and irrigated trials had four replications. The plot sizes varied across environments and years but were a minimum of two rows by $1.8 \mathrm{~m}$ long.

\section{Statistical Analysis}

In both the Nebraska and SCUS trials, data from each environment individually and also across environments within years were analyzed by Proc GLM (SAS Institute, 1989). Using Proc Mixed (Littell et al., 1996), line $\times$ environment, line $\times$ year, and line $\times$ environment $\times$ year interaction variances were estimated from the data on those lines that were evaluated in multiple years. In both the Nebraska and SCUS trials, genotypes were considered as fixed and environments as random. Irrigation in both trials was used to produce high yields so that the range in yields in each trial would encompass the range in performance observed by farmers in those regions in most years. In the across environment within year analyses of the SCUS data, the impact of irrigation and location was determined by the proportion of the locations and lines $X$ locations sources of variation that were attributable to these factors. Broad-sense heritability $(H)$ within each environment, which is the variance among lines divided by the phenotypic variance of a line mean, was calculated as $1-[$ (mean square for error $) /($ mean square for lines)].

Within each year, a test for COI was conducted for every pair of lines in every pair of environments. This resulted in $[n(n-1) e(e-1) / 4]$ tests, where $n$ is the number of lines and $e$ is the number of environments. An interaction was declared significant when the difference between the means of two lines $\left(X_{i}-X_{j}\right)$ was positive in one environment of the pair, negative in the other environment, and the absolute value of both differences was greater than $t_{0.16} \times$ the standard error of the difference $\left(\sigma_{\mathrm{d}}\right)$ between two means (Cornelius et al., 1992), which gives a $5 \%$ interaction-wise error rate. The distance between the $k$ th and $l$ th pair of environments $\left(D_{k l}\right)$ was defined as

$$
\begin{aligned}
D_{k l}= & \sum\left[\left(X_{i k}-X_{j k}\right)+\left(X_{i l}-X_{j l}\right)\right] \times 0.5 /\left(t_{0.16} \times \sigma_{\mathrm{d}}\right) \\
& \times 100,
\end{aligned}
$$

where $X_{\text {ik }}-X_{j k}=\left|X_{i k}-X_{j k}\right|$ if the interaction between $i$ th and $j$ th lines in the $k$ th environment was significant or $=0$ otherwise, and $X_{i l}-X_{j l}$ was similarly defined. This distance 
Table 1. Mean grain yields, values of heritability $(H)$, and significance of variation among 50 lines of winter wheat at four environments in Nebraska in 1998, 1999, and 2000.

\begin{tabular}{|c|c|c|c|c|c|c|c|c|c|}
\hline \multirow[b]{2}{*}{ Environments } & \multicolumn{3}{|c|}{ Mean yield } & \multicolumn{3}{|c|}{ Heritability $(H) \dagger$} & \multicolumn{3}{|c|}{$\begin{array}{c}\text { Significance of } \\
\text { variation among lines }\end{array}$} \\
\hline & 1998 & 1999 & 2000 & 1998 & 1999 & 2000 & 1998 & 1999 & 2000 \\
\hline & \multicolumn{3}{|c|}{$\mathrm{kg} \mathrm{ha}^{-1}$} & 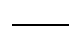 & $-\%$ & - & & & \\
\hline Lincoln & 5144 & 2874 & 3581 & 47.3 & 29.2 & 58.7 & $*$ & ns & $* *$ \\
\hline North Platte & 3838 & 4267 & - & 34.5 & 67.5 & - & ns & $* *$ & - \\
\hline Alliance & 4997 & 2973 & 3687 & 56.8 & 23.6 & 14.6 & $* *$ & ns & ns \\
\hline Sidney & 6711 & 4629 & 6043 & 58.7 & 64.1 & 66.0 & $* *$ & $* *$ & $* *$ \\
\hline Mean & 5172 & 3686 & 4437 & & & & & & \\
\hline
\end{tabular}

* Significant at $P<0.05$.

** Significant at $P<0.01$.

ns, Not significant at $P<0.05$.

$\dagger H=$ the variance among lines within an environment divided by the phenotypic variance of a line mean.

measure, which is the average value of the test statistic summed over all the significant pairwise interactions for a pair of environments, reflected both the frequency and the magnitudes of COIs.

Correlations of line means in a pair of environments have been used to investigate relationships among environments (Guitard, 1960; Campbell and Lafever, 1980; Peterson and Pfeiffer, 1989; Peterson, 1992). Therefore, for each pair of environments we compared distances derived from COIs to distance defined as $(1-r)$, where $r$ is the correlation of line means in one environment of the pair to the line means in the other environment. Also, we compared the COI distance to distance defined as the difference in mean yields between two environments. This comparison determined whether COIs were more likely to occur in a pair of environments when those environments differed substantially in mean yield than when the environments had similar yields and thus reexamined the issue of selecting in low-stress versus high-stress environments.

\section{RESULTS}

\section{Nebraska Regional Trial}

Across years, the lowest mean yield occurred in 1999 and the highest in 1998 (Table 1). All environments exhibited this same trend, except for North Platte, at which the lowest yield occurred in 1998 and the highest in 1999 (no data from North Platte in 2000). The highest yielding environment every year was Sidney, the irrigated location, whereas the environment with the lowest yield varied from year to year. The difference between the lowest and highest yielding environments within years expressed as a percentage of the lowest yielding environment ranged from $61 \%$ in 1998 to $75 \%$ in 1999 . In comparison, from 1985 through 2004, the percentage difference between the lowest and highest statewide average yields of winter wheat in Nebraska was $78 \%$ (National Agricultural Statistics Service, 2005). In terms of mean performance, it appears that within each year a wide range of the target environmental space was being sampled.

The variation among lines was highly significant at Sidney each year (Table 1), whereas this variation was not significant at Alliance in either 1999 or 2000, at North Platte in 1998, or at Lincoln in 1999. Each of the environments with nonsignificant line variation had a low mean yield. Values of $H$ were positively correlated with mean yields. Across years, the highest values of $H$ occurred at Sidney, whereas the three lowest values of $H$ occurred at environments with yields less than the mean.

Seventeen lines were evaluated in more than $1 \mathrm{yr}$, which provided 142 unique year-environment line means. From these data, estimates of both the line $\times$ year and line $\times$ environment variances were zero, whereas the line $\times$ environment $\times$ year interaction variance was significantly greater than zero. This result suggested that with respect to interaction with lines, as much variation occurred among environments within years as among environments in different years.

In the analyses across environments but within years (Table 2), the line $\times$ environment mean squares were highly significant every year and were of sufficient magnitude that the variation among lines was not significant when compared with this line $\times$ environment interaction in any year. This nonsignificance occurred because the correlations of line means at pairs of environments were small. Only one of these correlations was significantly different from zero, and this was a negative correlation $(r=-0.29 *)$ that occurred between Lincoln and Alliance in 1999.

Table 2. Mean squares from an analysis of variance of 50 lines of winter wheat evaluated for grain yield across four (1998 and 1999$)$ or three (2000) environments in Nebraska.

\begin{tabular}{|c|c|c|c|c|c|c|c|c|c|}
\hline \multirow[b]{2}{*}{ Source of variation } & \multicolumn{3}{|c|}{1998} & \multicolumn{3}{|c|}{1999} & \multicolumn{3}{|c|}{2000} \\
\hline & df & Mean square & Significance & df & Mean square & Significance & df & Mean square & Significance \\
\hline & \multicolumn{3}{|c|}{$\left(\mathrm{kg} \mathrm{ha}^{-1}\right)^{2} \times 10^{3}$} & \multicolumn{3}{|c|}{$\left(\mathrm{kg} \mathrm{ha}^{-1}\right)^{2} \times 10^{3}$} & \multicolumn{3}{|c|}{$\left(\mathrm{kg} \mathrm{ha}^{-1}\right)^{2} \times 10^{3}$} \\
\hline Environments & 3 & 139360.4 & $* *$ & 3 & 79759.4 & $* *$ & 2 & 193789.0 & $* *$ \\
\hline Lines & 49 & 1058.9 & ns & 49 & 759.6 & ns & 49 & 893.4 & ns \\
\hline Lines $\times$ environments & 147 & 798.5 & $* *$ & 147 & 582.3 & $* *$ & 98 & 1114.0 & $* *$ \\
\hline Pooled error $\dagger$ & 196 & 367.6 & & 196 & 291.2 & & 147 & 427.9 & \\
\hline
\end{tabular}

*** Significant at $\boldsymbol{P}<\mathbf{0 . 0 1}$.

ns. and not significant at $P<0.05$.

$\dagger$ Error terms from individual environments were heterogeneous in both 1998 and 2000. 
Table 3. Frequency of significant cross-over interactions (COIs) among pairs of 50 lines of winter wheat evaluated for grain yield in Nebraska.

\begin{tabular}{|c|c|c|c|c|c|c|c|}
\hline \multirow[b]{2}{*}{ Year } & \multicolumn{7}{|c|}{ Pairs of environments $\dagger$} \\
\hline & $\begin{array}{c}\text { Lincoln; } \\
\text { North } \\
\text { Platte }\end{array}$ & $\begin{array}{l}\text { Lincoln; } \\
\text { Alliance }\end{array}$ & $\begin{array}{l}\text { Lincoln; } \\
\text { Sidney }\end{array}$ & $\begin{array}{l}\text { North } \\
\text { Platte; } \\
\text { Alliance }\end{array}$ & $\begin{array}{l}\text { North } \\
\text { Platte; } \\
\text { Sidney }\end{array}$ & $\begin{array}{l}\text { Alliance; } \\
\text { Sidney }\end{array}$ & $\begin{array}{c}\text { All } \\
\text { pairs }\end{array}$ \\
\hline 1998 & $142 \S$ & 145 & 116 & 86 & 108 & 236 & 833 \\
\hline 1999 & 148 & 156 & 165 & 123 & 125 & 51 & 768 \\
\hline 2000 & $-\div$ & 132 & 201 & $-\%$ & $-\div$ & 174 & 507 \\
\hline
\end{tabular}

$\dagger$ Expected number of significant COIs as a result of Type 1 errors $(P=$ 0.05 ) was 61 in each pair of environments.

$\$$ Data from North Platte was discarded in 2000 because of hail damage.

\$ A COI was declared significant when the difference between the means of two lines was positive in one environment of the pair, negative in the other environment, and both differences were greater than $t_{0.16} \times$ the standard error of the difference $\left(\sigma_{d}\right)$ between two means (Cornelius et al., 1992).

On the basis of a $t$ test with an interaction-wise error rate of $5 \%$, the numbers of COIs were 833 and 768 in 1998 and 1999 out of a possible 7350 interactions and 507 in 2000 out of a possible 3675 interactions (Table 3 ). The expected number of falsely declared significant COIs (Type 1 errors) was 368 in 1998 and 1999 and 184 in 2000 (a mean of 61 per pair of environments in each year). The observed numbers of significant COIs were substantially greater than these numbers each year, indicating the likely presence of real changes in ranks of lines across environments. Every pair of environments in every year, except Alliance and Sidney in 1999, had more COIs than were expected as the result of Type 1 errors, so the occurrence of this type of interaction was widespread and not limited only to certain pairs of environments or to some years. Furthermore, for the five best lines at each environment in each year, the mean rank of these lines at all the other environments in the same year was 22.5, only slightly greater than the median rank of 25.5. These results indicated that COIs were not solely the result of ranks changing among relatively nonelite lines but that elite lines also were involved in changes in ranks.

The relative COI-based distance between environments showed considerable differences across years (Table 4). The most extreme example of these differences existed for the distance between Alliance and Sidney, which had the greatest value of any distance in both 1998 and 2000 but the smallest value in 1999. The COI distances exhibited some similarity to the distances
Table 4. Distances between pairs of Nebraskan environments based on simple correlations [above diagonal] or cross-over interactions (COIs) [below diagonal] among 50 lines of winter wheat evaluated for grain yield.

\begin{tabular}{|c|c|c|c|c|}
\hline & Lincoln & North Platte & Alliance & Sidney \\
\hline \multicolumn{5}{|l|}{ 1998: } \\
\hline Lincoln & & 1.01 & 0.92 & 0.86 \\
\hline North Platte & $5.04 \dagger$ & & 0.77 & 0.80 \\
\hline Alliance & 5.32 & 3.14 & & 1.13 \\
\hline Sidney & 4.36 & 3.53 & 9.33 & \\
\hline 1999: & & & & \\
\hline Lincoln & & 0.93 & 1.29 & 1.06 \\
\hline North Platte & 5.66 & & 0.93 & 0.73 \\
\hline Alliance & 5.22 & 4.24 & & 0.75 \\
\hline $\begin{array}{l}\text { Sidney } \\
\text { 2000: }\end{array}$ & 5.82 & 4.68 & 1.50 & \\
\hline Lincoln & & & 1.06 & 1.00 \\
\hline Alliance & 4.76 & & & 1.19 \\
\hline Sidney & 7.86 & & 6.61 & \\
\hline
\end{tabular}

$\uparrow$ Distance based on COI equals the average value of the test statistic for COI that was defined by Cornelius et al. (1992) summed over all the significant pairwise interactions for a pair of environments.

calculated as $1-r$ (Table 4$)$, as the correlation between these two measures of distance across all pairs of environments was 0.64 , which was significantly greater than zero. However, some notable differences between them occurred. For example, on the basis of $1-r$, the greatest distance was between Alliance and Lincoln in 1999, but on the basis of COI, the distance between these two environments was only average compared with the COI distance for other pairs of environments.

The correlation between COI distance and distance defined as the difference in mean yield between environments was even less at 0.16 . This low value, which was not significantly different from zero, occurred because the largest difference in mean yields within years existed between Sidney and North Platte in 1998 (2873 $\mathrm{kg} \mathrm{ha}^{-1}$ ), but this pair of environments had a relatively small COI distance. Also, the smallest difference in yield existed between Lincoln and Alliance in 1999 (99 kg $\mathrm{ha}^{-1}$ ), but this environmental pair had a relatively large COI distance.

\section{SCUS Regional Trial}

Across all environments and years, the mean grain yield was $12 \%$ less in the SCUS than in the Nebraska regional trial. Yields were low in both 1998 and 2000 and high in 1999 (Table 5). The highest yielding environment in every year was Bushland-irrigated (I), whereas the

Table 5. Mean grain yields, values of heritability $(H)$, and significance of variation among 45 lines of winter wheat at four environments in south-central USA in 1998, 1999, and 2000.

\begin{tabular}{|c|c|c|c|c|c|c|c|c|c|}
\hline \multirow[b]{2}{*}{ Environments } & \multicolumn{3}{|c|}{ Mean yield } & \multicolumn{3}{|c|}{ Heritability $(\boldsymbol{H}) \dagger$} & \multicolumn{3}{|c|}{$\begin{array}{c}\text { Significance of variation } \\
\text { among lines }\end{array}$} \\
\hline & 1998 & 1999 & 2000 & 1998 & 1999 & 2000 & 1998 & 1999 & 2000 \\
\hline & $\longrightarrow$ & $\operatorname{kg~ha}{ }^{-1}$ & - & $\longrightarrow$ & $-\%-$ & - & & & \\
\hline Bushland, TX (NI) $\dagger$ & 2468 & 3803 & 3064 & 88.4 & 60.1 & 93.4 & $* *$ & $* *$ & $* *$ \\
\hline Bushland, TX (I)† & 5378 & 6302 & 4129 & 92.0 & 81.0 & 88.5 & $* *$ & $* *$ & *** \\
\hline Clovis, NM (NI) & 2063 & 4011 & 2023 & 23.2 & 49.5 & 46.0 & ns & $* *$ & $* *$ \\
\hline Clovis, NM (I) & 3536 & 6054 & 3861 & 90.9 & 71.4 & 48.7 & $* *$ & $* *$ & $* *$ \\
\hline Mean & 3361 & 5042 & 3269 & & & & & & \\
\hline
\end{tabular}

** Significant at $\boldsymbol{P}<\mathbf{0 . 0 1}$.

$\dagger \mathbf{N I}=$ nonirrigated; $\mathbf{I}=$ irrigated.

$\dagger H=$ the variance among lines within an environment divided by the phenotypic variance of a line mean. 
Table 6. Mean squares from an analysis of variance of 45 lines of winter wheat evaluated for grain yield across four environments in southcentral USA.

\begin{tabular}{|c|c|c|c|c|c|c|c|c|c|}
\hline \multirow[b]{2}{*}{ Source of variation } & \multirow[b]{2}{*}{ df } & \multicolumn{2}{|c|}{1998} & \multirow[b]{2}{*}{ df } & \multicolumn{2}{|c|}{1999} & \multicolumn{3}{|c|}{2000} \\
\hline & & Mean square & Significance & & Mean square & Significance & df & Mean square & Significance \\
\hline & & $\left(\mathrm{kg} \mathrm{ha}^{-1}\right)^{2} \times 10^{3}$ & & & $\left(\mathrm{~kg} \mathrm{ha}^{-1}\right)^{2} \times 10$ & & & $\left(\mathrm{~kg} \mathrm{ha}^{-1}\right)^{2} \times 10$ & \\
\hline Environments & 3 & 98746.3 & ** & 3 & $\mathbf{7 8 1 5 5 . 0}$ & ** & 3 & 60420.2 & $* *$ \\
\hline Locations & 1 & 56854.8 & ** & 1 & 17.8 & ns & 1 & 19240.8 & ** \\
\hline Irrigation & 1 & 216149.7 & ** & 1 & 232113.2 & ** & 1 & 94799.8 & ** \\
\hline Locations $\times$ irrigation & 1 & 23234.5 & $* *$ & 1 & 2333.9 & ** & 1 & 67220.0 & ** \\
\hline Lines & 44 & 1062.0 & $* *$ & 44 & 1390.7 & ** & 44 & 600.0 & ** \\
\hline Lines $\times$ environments & 132 & 242.1 & ** & 132 & 505.8 & ** & 132 & 180.4 & $* *$ \\
\hline Lines $\times$ locations & 44 & 115.9 & ns & 44 & 719.3 & ** & 44 & 266.3 & $* *$ \\
\hline Lines $\times$ irrigation & 44 & 420.5 & ** & 44 & 446.6 & ** & 44 & 148.6 & $* *$ \\
\hline Lines $\times$ locations $\times$ irrigation & 44 & 189.8 & ** & 44 & 351.6 & ** & 44 & 126.4 & ** \\
\hline Pooled error $\dagger$ & 440 & 126.4 & & 352 & 229.2 & & 352 & 83.3 & \\
\hline
\end{tabular}

** Significant $\boldsymbol{P}<\mathbf{0 . 0 1}$.

ns, not significant at $P<0.05$.

$\dagger$ Error terms from individual environments were heterogeneous in each year.

lowest mean yield each year occurred at one of the two nonirrigated (NI) locations. The difference between the lowest and highest yielding environments within years expressed as a percentage of the lowest yielding environment ranged from $66 \%$ in 1999 to $104 \%$ in 2000 . Hence, as observed in the Nebraska trial, a wide range in mean yields among environments was seen each year.

Variation among lines was highly significant in every individual environment except Clovis (NI) in 1998, where the variation was nonsignificant (Table 5). The second lowest mean yield in this data set occurred at this environment. Except at Bushland in 2000, the irrigated trials had higher values of $H$.

In this trial, there were 156 unique year-environment line means available for estimation of line $\times$ environment, line $\times$ year, and line $\times$ environment $\times$ year variances. As in the Nebraska data, the estimate of the line $\times$ year variance was zero. The line $x$ environment variance was positive but was less than $25 \%$ as large as the line $\times$ environment $\times$ year variance.

In the high-yielding year of 2000, the mean yield of the two Clovis environments was nearly equal to the mean yield of the two Bushland environments, and thus $99 \%$ of the variation among environments was attributable to the irrigation factor (Table 6). In both lowyielding years, the mean yield of the two Bushland environments was higher than the mean yield of the two Clovis environments, although the impact of irrigation on the variation among environments was still considerably greater than that of location. However, in both 1999 and 2000, the mean square of the line $\times$ location in- teraction was significantly greater than the mean square of the line $\times$ irrigation interaction. This result indicated that some factor(s) specific to location was important in causing lines to respond differentially at Clovis and Bushland in these $2 \mathrm{yr}$.

Contrary to what was observed in the Nebraska trials, in the across-environment within-year analyses the variation among lines was highly significant each year (Table 6). All the correlations between line means at different environments within years were positive and nearly two-thirds were significantly greater than zero. Across years, the highest mean correlation was between Bushland (NI) and Bushland (I), and this correlation was significantly greater than zero each year. The correlation between the two Clovis environments also was significant each year, whereas the correlation between the two irrigated environments was highly significant $2 \mathrm{yr}$ but not significant in the other year. The lowest mean correlation occurred between line means at the two nonirrigated environments, and this correlation was not significantly different from zero in any year.

Overall, the frequency of COIs was less in this data set than in the Nebraska trial. In 1999, the high-yielding year, 273 significant interactions were observed, which was less than the 297 expected as a result of Type 1 errors with a 5\% error rate (Table 7). In both 1998 and 2000 , the frequency of significant interactions across all environmental pairs suggested that real COIs existed, but even in these years there was not evidence of COIs in some pairs of environments. Unlike in the Nebraska trial, several patterns in the frequencies of COIs

Table 7. Frequency of significant cross-over interactions (COIs) among pairs of 45 lines of winter wheat evaluated for grain yield in south-central USA.

\begin{tabular}{|c|c|c|c|c|c|c|c|}
\hline \multirow[b]{2}{*}{ Year } & \multicolumn{7}{|c|}{ Pairs of environments $\dagger, \ddagger$} \\
\hline & $\begin{array}{c}\text { Bushland, TX (NI); } \\
\text { Bushland, TX (I) }\end{array}$ & $\begin{array}{c}\text { Bushland, TX (NI); } \\
\text { Clovis, NM (NI) }\end{array}$ & $\begin{array}{c}\text { Bushland, TX (NI); } \\
\text { Clovis, NM (I) }\end{array}$ & $\begin{array}{l}\text { Bushland, TX (I); } \\
\text { Clovis, NM (NI) }\end{array}$ & $\begin{array}{c}\text { Bushland, TX (I); } \\
\text { Clovis, NM (I) }\end{array}$ & $\begin{array}{l}\text { Clovis, NM (NI); } \\
\text { Clovis, NM (I) }\end{array}$ & All pairs \\
\hline 1998 & $67 \S$ & 98 & 141 & 8 & 35 & 36 & 385 \\
\hline 1999 & 21 & 36 & 106 & 19 & 45 & 46 & 273 \\
\hline 2000 & 38 & 146 & 77 & 66 & 33 & 50 & 410 \\
\hline
\end{tabular}

$\dagger$ Expected number of significant COIs as a result of Type 1 errors $(P=0.05)$ was 50 in each pair of locations.

$\$ \mathbf{N I}=$ nonirrigated; $\mathbf{I}=$ irrigated.

$\$$ A COI was declared significant when the difference between the means of two lines was positive in one environment of the pair, negative in the other environment, and both differences were greater than $t_{0.16} \times$ the standard error of the difference $\left(\sigma_{\mathrm{d}}\right)$ between two means (Cornelius et al., 1992). 
Table 8. Distances between pairs of environments in south-central USA based on simple correlations [above diagonal] or crossover interactions (COIs) [below diagonal] among 45 lines of winter wheat evaluated for grain yield.

\begin{tabular}{|c|c|c|c|c|}
\hline & $\begin{array}{l}\text { Bushland, } \\
\text { TX (NI) } \dagger\end{array}$ & $\begin{array}{c}\text { Bushland, } \\
\text { TX (I) } \dagger\end{array}$ & $\begin{array}{l}\text { Clovis, } \\
\text { NM (NI) }\end{array}$ & $\begin{array}{l}\text { Clovis, } \\
\text { NM (I) }\end{array}$ \\
\hline \multicolumn{5}{|l|}{ 1998: } \\
\hline Bushland, TX (NI) & & 0.67 & 0.76 & 0.50 \\
\hline Bushland, TX (I) & $3.62 \ddagger$ & & 0.41 & 0.22 \\
\hline Clovis, NM (NI) & 4.08 & 0.27 & & 0.43 \\
\hline Clovis, NM (I) & $\mathbf{7 . 5 3}$ & 3.53 & 1.25 & \\
\hline \multicolumn{5}{|l|}{ 1999: } \\
\hline Bushland, TX (NI) & & 0.48 & 0.71 & 0.79 \\
\hline Bushland, TX (I) & 0.81 & & 0.72 & 0.71 \\
\hline Clovis, NM (NI) & 1.21 & 0.77 & & 0.42 \\
\hline Clovis, NM (I) & 4.09 & 4.68 & 1.55 & \\
\hline \multicolumn{5}{|l|}{ 2000: } \\
\hline Bushland, TX (NI) & & 0.32 & 0.82 & 0.47 \\
\hline Bushland, TX (I) & 1.65 & & 0.96 & 0.62 \\
\hline Clovis, NM (NI) & 6.58 & 6.61 & & 0.63 \\
\hline Clovis, NM (I) & 3.18 & 3.14 & 1.48 & \\
\hline
\end{tabular}

$\dagger \mathbf{N I}=$ nonirrigated; $\mathbf{I}=$ irrigated.

$\leftarrow$ Distance based on COI equals the average value of the test statistic for COI that was defined by Cornelius et al. (1992) summed over all the significant pairwise interactions for a pair of environments.

emerged. A low and likely nonsignificant frequency of COI occurred between the two irrigated environments each year. Another pattern was a relatively high frequency of COIs between Clovis (I) and Bushland (NI) in every year. The effect of fewer COIs in this data set also was reflected in greater consistency of performance of elite entries across environments. In 1998, one entry ranked in the top five entries in every environment, and in both 1999 and 2000 there was an entry that ranked in the top five in three of the four environments. This level of consistency was not observed in the Nebraska data set in any year.

The correlation between the COI-based distances and those calculated as $1-r$ was only 0.35 (Table 8 ), which was less than this correlation in the Nebraska trial and was not significantly different from zero. An example of the poor correspondence between these two measures was the association in 1999 between Clovis (NI) and the two Bushland environments. For each of these environmental pairs, the correlation between line means was not significantly different than zero. This low correlation might be interpreted as an indication of significant COIs. However, in both of these environmental pairs, the number of significant COIs was less than the number expected by chance. The correlation between the COI distances and distances defined as the difference in mean yield between environments was -0.23 , which was not significant. This result indicated that the frequency and/or magnitudes of COIs was not any greater between a low-stress and a high-stress environment than between two low-stress or two high-stress environments.

\section{DISCUSSION}

The goal of this research was to gain a better understanding of the relationship among testing environments, particularly in terms of COIs, in two regional trials of winter wheat. In the Nebraska trial, significant frequencies of COIs were found between all pairs of environments in each year except for one. This resulted in the variation among lines in the analysis of variance across environments being nonsignificant each year compared with the line $\times$ environment interaction, even though in most of the within environment analyses the variation among lines was significant. Do these results dictate that a separate breeding program be initiated for each location?

There are two difficulties with such an approach. First, as noted by Atlin et al. (2000), unless the line $\times$ environment variance is large relative to the variance among lines, any advantage resulting from selection for specific adaptation will be overshadowed from loss in precision due to less testing in these smaller zones of adaptation relative to testing across all environments. Second, our analysis across years and environments suggested that the largest component of the line $\times$ environment interaction in the Nebraska trial was the line $\times$ environment $\times$ year variance. In fact, estimates of line $\times$ environment and line $\times$ year variances for this trial were zero. The great relative importance of the three-way interaction, which has been observed in other trials of small grains (Atlin et al., 2000), suggests that had all lines been evaluated in all environments and years that the frequency of COIs would have been as high between two environments that were the same location in different years as between two environments (different locations) in the same year. Under this situation, selecting for local adaptation would not be expected to carry over from year to year. Although the frequency of COIs was relatively high in the Nebraska trial, these results do not support breeding for local adaptation. However, neither should the COIs be totally ignored. A prudent breeding approach would be to identify the best lines on the basis of mean performance across all environments and then from among those select the lines involved in the fewest number of significant COIs. For example, in 1998, the check 'Abilene' and experimental line NI97405 had nearly identical mean yields and were among the best $15 \%$ of the lines, but Abilene was involved in substantially fewer significant COIs than was NI97405. Abilene should be favored over NI97405.

Frequency of COIs in the SCUS data set was less than in Nebraska. Every year the variation among lines was highly significant and also a line occurred every year that ranked in the top five in at least three of the four environments. Averaged across years, a significant frequency of COIs occurred only between Clovis (NI) and Bushland (NI) and between Clovis (I) and Bushland (NI). Minimally, these results would support combining data across the two Clovis environments and across the two Bushland environments, and selecting for performance across all environments could even be justified. This result was not entirely unexpected as Clovis and Bushland are geographically close.

Because each location in this data set had two environments, one irrigated and one nonirrigated, the impact of water on COI could be tested directly. Irrigation had a greater relative impact on variation of grain yield among environments than on the line $\times$ environmental interaction. The frequency of COIs between irrigated and nonirrigated environments at both locations was 
less than expected from Type 1 errors. This result leads to the conclusion that water was not a primary causative factor of COIs, even though water was the major variable associated with differences in mean environmental yields.

In both the Nebraska and SCUS trials, the results were influenced by the lines that were evaluated. At least $95 \%$ of the lines were semidwarf types in both trials. Tall wheat lines historically have had their best performances in drier environments, such as occur in western Nebraska. Therefore, inclusion of more tall lines in these trials may have resulted in a greater frequency of COIs than was observed. Also, an important difference between the lines in the two trials was that the majority of the lines in the Nebraska trial were first-year experimental lines, whereas the lines in the SCUS trial were elite lines that had previously been selected in state breeding programs and thus had more selection for adaptation to variable environments. This difference in the selection history of the lines in these two trials may explain partly the greater frequency of COIs in the Nebraska trial.

The correlation between COI-based distance and distance calculated as $1-r$ was positive in both trials but particularly in the SCUS trial was not large. Different conclusions about the relationships between environments would have been reached had correlations between line means rather than COI been used to assess similarity. Peterson (1992) used a correlation matrix to study the relationships among a large number of locations on the basis of yield results from many years of the winter wheat Southern and Northern Regional Performance Nurseries, including most of the locations used in this research. His results suggested that the relationship among the Nebraska locations exhibited some east-west orientation. Such an orientation was not apparent on the basis of our COI distances for the fewer years used in this study. However, a confounding factor in comparing the results from these two studies is that in our study the trials at Sidney were irrigated, whereas in the Peterson study there were not.

One of the more interesting results from our research was the absence of line $\times$ year interaction in both trials. In comparison, across nine trials of small grains the mean value of the line $\times$ year variance was $6 \%$ of the phenotypic variance (Atlin et al., 2000). Assuming our estimates were not biased (in each trial only a subset of the lines was analyzed across both environments and years), the implication is that testing across multiple years can effectively be replaced by testing across additional environments within years. For example, evaluation at eight representative environments in $1 \mathrm{yr}$ would be as predictive of future performance in the environmental space as evaluation of four representative environments across a 2-yr period. Additional estimates of line $\times$ year variances from larger data sets should be obtained for wheat trials in both Nebraska and in the south-central USA to verify this finding.

Another surprising result observed in both trials was the low correlation between COI distance and distance measured as the difference in mean yield between two environments. During the past several decades, a common approach to visualizing genotype $\times$ environment interaction has been to regress line means on an environmental index, which is usually the environmental mean (Finlay and Wilkinson, 1963; Eberhart and Russell, 1966). Lines with different slopes are said to have different sensitivities to stress. Often in these analyses of yield in wheat and other crops, significant variation for slopes among genotypes has been observed (Eberhart and Russell, 1969; Joppa et al., 1971; Baihaki et al., 1976; Fufa et al., 2005). The likelihood that two lines with different slopes will intersect, which implies a COI, is expected to increase as the difference between the highest and lowest environmental means increases. Our finding contradicted this conclusion because the correlation between frequency of COIs and the difference between environmental means was low. With respect to the ranking of lines in the environments of the Nebraska and SCUS trials, the classification of environments as low- or high-stress did not appear to have much relevance. This conclusion might be different with different sets of wheat lines that included more tall lines.

Are the COIs observed in these trials only a nuisance, or can breeders use them to their advantage? To use them, breeders must determine the causative environmental factors. If only a few factors account for much of the COIs and if these factors can be controlled, then knowledge of them should increase breeding efficiency. For example, if a particular disease is a primary causative factor, then a breeder could specifically test for reaction to this disease in a nursery that was inoculated with the disease agent and also test for grain yield only at a few sites where the disease does not occur and where there is a history of obtaining high values of $H$. What factors caused the COIs observed in these two regional trials are not clear. Differential sensitivity among lines to one or more pathogens seems unlikely, as significant levels of any disease were so sporadic that no disease notes were taken at any environment in the Nebraska trial and notes were taken only on leaf rust and only at 3 of the 12 environment $\times$ year evaluations in the SCUS trial. Levels of lodging also were generally low in both trials. Determining causative factors of COI will require either experiments where potential factors are controlled or analysis of historical data sets where accompanying data on numerous environmental variables exist.

\section{REFERENCES}

Allen, F.L., R.F. Comstock, and D.C. Rasmusson. 1978. Optimal environments for yield testing. Crop Sci. 18:747-751.

Atlin, G.N., R.J. Baker, K.B. McRae, and X. Lu. 2000. Selection response in subdivided Target regions. Crop Sci. 40:7-13.

Atlin, G.N., and K.J. Frey. 1989. Predicting the relative effectiveness of direct versus indirect selection for oat yield in three types of stress environments. Euphytica 44:137-142.

Azzalini, A., and D.R. Cox. 1984. Two new tests associated with analysis of variance. J. Roy. Statist. Soc. B 46:335-343.

Baihaki, A., R.E. Stucker, and J.W. Lambert. 1976. Association of genotype $X$ environment interactions with performance level of soybean lines in preliminary yield tests. Crop Sci. 16:718-721. 
Baker, R.J. 1988. Tests for crossover genotype-environmental interactions. Can. J. Plant Sci. 68:405-410.

Braun, H.J., S. Rajaram, and M. van Ginkel. 1996. CIMMYT's approach to breeding for wide adaptation. Euphytica 92:175-183.

Byrne, J., P.F. Balaños, G.O. Edmeades, and D.L. Eaton. 1995. Gains from selection under drought versus multilocation testing in related tropical maize populations. Crop Sci. 35:63-69.

Campbell, L.G., and H.N. Lafever. 1980. Effects of locations and years upon relative yields in the soft red winter wheat region. Crop Sci. 20:23-28.

Ceccarelli, S. 1994. Specific adaptation and selection for marginal conditions. Euphytica 77:205-219.

Ceccarelli, S., and S. Grando. 1996. Drought as a challenge for the plant breeder. Plant Growth Regul. 20:149-155.

Cornelius, P.L., M. Seyedsadr, and J. Crossa. 1992. Using the shifted multiplicative model to search for "separability" in crop cultivar trials. Theor. Appl. Genet. 84:161-172.

Eberhart, S.A., and W.A. Russell. 1966. Stability parameters for comparing varieties. Crop Sci. 6:36-40.

Eberhart, S.A., and W.A. Russell. 1969. Yield and stability for a 10-line diallel of single-cross and double-cross maize hybrids. Crop Sci. 9:357-361.

Finlay, K.W., and G.N. Wilkinson. 1963. The analysis of adaptation in a plant-breeding programme. Aust. J. Agric. Res. 14:742-754.

Fox, P.N., and A.A. Rosielle. 1982. Reducing the influence of environmental main- effects on pattern analysis of plant breeding environments. Euphytica 31:645-656.

Frey, K.J. 1964. Adaptation reaction of oat strains selected under stress and non-stress environmental conditions. Crop Sci. 4:55-58.

Fufa, H., P. Stephen Baenziger, B.S. Beecher, R.A. Graybosch, K.M. Eskridge and L.A. Nelson. 2005. Genetic Improvement Trends in Agronomic Performances and End-use Quality Characteristics Among Hard Red Winter Wheat Cultivars in Nebraska. Euphytica 144:187-198.

Gail, M., and R. Simon. 1985. Testing for qualitative interactions between treatment effects and patient subsets. Biometrics 41:361-372.

Gauch, H.G., and R.W. Zobel. 1988. Predictive and postdictive success of statistical analyses of yield trials. Theor. Appl. Genet. 76: $1-10$.
Guitard, A.A. 1960. The use of diallel correlations for determining the relative locational performance of varieties of barley. Can. J. Plant Sci. 40:645-651.

Haldane, J.B.S. 1946. The interaction of nature and nurture. Ann. Eugen. 13:197-205.

Johnson, S.S., and J.L. Geadelmann. 1989. Influence of water stress on grain yield response to recurrent selection in maize. Crop Sci. 29: $558-564$.

Joppa, L.R., K.L. Lebsock, and R.H. Busch. 1971. Yield stability of selected spring wheat cultivars (Triticum aestivum L. em Thell) in the uniform regional nurseries, 1959 to 1968. Crop Sci. 11: 238-241.

Littell, R.C., G.A. Milliken, W.W. Stroup, and R.D. Wolfinger. 1996. SAS system for mixed models. SAS Institute Inc., Cary, NC.

National Agricultural Statistics Service. 2005. QuickStats [Online]. Available at http://www.nass.usda.gov/QuickStats (verified 3 February 2006).

Nebraska Agricultural Statistics Service. 2002. Annual report. USDA, Lincoln, NE.

Peterson, C.J. 1992. Similarities among test sites based on cultivar performance in the hard red winter wheat region. Crop Sci. 32: 907-912.

Peterson, C.J., and W.H. Pfeiffer. 1989. International winter wheat evaluation: Relationships among test sites based on cultivar performance. Crop Sci. 29:276-282.

Rosielle, A.A., and J. Hamblin. 1981. Theoretical aspects of selection for yield in stress and non-stress environments. Crop Sci. 21: 943-946.

Russell, W.K., K.M. Eskridge, D.A. Travnicek, and F.R. GuillenPortal. 2003. Clustering of environments to minimize change in rank of cultivars. Crop Sci. 43:858-864.

SAS Institute Inc. 1989. SAS/STAT user's guide (version 6, 4th ed.). SAS Institute Inc., Cary, NC.

Shabana, R., T. Bailey, and K.J. Frey. 1980. Production traits of oats selected under low, medium, and high productivity. Crop Sci. 20: 739-744.

van Oosterom, E.J., D. Kleijn, S. Ceccarelli, and M.M. Nachit. 1993. Genotype-by-environment interactions of barley in the Mediterranean region. Crop Sci. 1993:669-674. 